Original Research Article

\title{
A study on antimicrobial agents utilization pattern using anatomical therapeutic chemical / daily defined dose system and adverse drug reaction pattern in the intensive care unit of a tertiary care teaching hospital in North Eastern state of India
}

\author{
Debasis Ray ${ }^{1 *}$, Smita $_{\text {Datta }}^{2}$
}

${ }^{1}$ Department of Pharmacology, ${ }^{2}$ MBBS Student, Agartala Govt. Medical College, Agartala, Tripura, India

Received: 29 May 2018 Accepted: 26 June 2018

\section{*Correspondence to: \\ Dr. Debasis Ray, Email: contactdebasisray@ gmail.com}

Copyright: (C) the author(s), publisher and licensee Medip Academy. This is an openaccess article distributed under the terms of the Creative Commons Attribution NonCommercial License, which permits unrestricted noncommercial use, distribution, and reproduction in any medium, provided the original work is properly cited.

\begin{abstract}
Background: Successful use of antibiotics has brought a revolutionary change in the management of infectious diseases but has also resulted in its irrational use. Indiscriminate use of anti-microbial agents (AMAs) has been well-documented in the ICUs where polypharmacy is a common phenomenon, thus increasing the risk of Adverse Drug Reactions (ADRs). It is extremely imperative to evaluate the prescribing pattern of antimicrobials for enabling suitable modifications in prescribing patterns; to increase the therapeutic benefits and for optimizing the health care services.

Methods: With the objective to assess the prescription patterns of AMAs and the rationality of their use this observational study was undertaken in the Intensive Care Unit of a Tertiary Care Hospital for two months.

Results: Of the total 127 patients, $80(62.99 \%)$ were male and $47(37.01 \%)$ were female at an average age of $51.3 \pm 18.3$ years. $102(80.31 \%)$ patients received AMAs at average of $1.71 \pm 0.99$ and 25 (19.69\%) didn't. Betalactam antibiotics were the most frequently $(72.99 \%)$ prescribed class. Meropenem was the most commonly prescribed (41 occasions) agent. The length of stay in ICU per patient was $4.42 \pm 3.49$ days. $41.63 \%$ patients had more than two morbidities. No AMAs were prescribed in generic name. In $28(27.45 \%)$ patients the AMAs prescribing were irrational.

Conclusions: The high utilization rates of costly AMAs and irrational prescriptions are matters of great concern and need to be urgently addressed by use of guidelines, surveillance and antibiotic restriction policies and sensitization programs at all level of healthcare.
\end{abstract}

Keywords: Antibiotic utilization, ADR, DDD, ICU, Rationality

\section{INTRODUCTION}

Successful use of antibiotics has brought a revolutionary change in management of infectious diseases. ${ }^{1}$ About 5000 antimicrobial agents (AMAs) have been discovered till date, out of which only around 100 are used clinically for treating infection. ${ }^{2}$ AMAs deserve their place as one of the most powerful pillars of modern medical care. ${ }^{3}$ Antimicrobial agents are prescribed very often inappropriately and they have become one of the highly abused drugs. This widespread and indiscriminate use of antimicrobial agents inevitably has resulted in the emergence of antibiotic resistant pathogens. ${ }^{4}$ All these issues produced a great concern all over the world. ${ }^{4}$

Antibiotics are the most frequently prescribed drugs especially in Intensive care Units (ICU). Total AMA consumption in ICU is approximately ten times higher than the general hospital wards. ${ }^{2,5}$ Extensive and indiscriminate use of AMAs has been documented in 
ICUs. ${ }^{6}$ The problem of resistance is greater in ICUs than in other hospital wards. ${ }^{7}$

There is continuing emergence of resistant pathogen and unfortunately, as the need for new AMA has grown over time, development of novel drugs has been slow in the recent years. ${ }^{2}$ Drug utilization study is a great tool for analyzing and evaluating prescribing pattern of medical professionals and also helps in formulating drug and antibiotics policy. ${ }^{1}$ The ICU has been known to be the land of polypharmacy. The critically ill patients in ICU are more vulnerable to ADRs than others. ${ }^{8}$

Occurrence of ADRs in all hospitalized patients is about $10-20 \%$ and $30-80 \%$ of all ADRs are preventable. Median under-reporting rate for all ADRs in hospital is 94\%. ADRs are complex issues, which require special attention. Studying the ADRs becomes important to give better patient care. There is paucity of data regarding ADR monitoring especially in relation to drugs used in the ICUs. ${ }^{8,9}$

Widespread overuse and inappropriate use of antimicrobial drugs (AMD) is an important factor for increase in antimicrobial resistance. ${ }^{10}$

Drug utilization study is a component of medical audit which monitor and evaluate the drug prescribing patterns. ${ }^{6}$ It is extremely imperative to evaluate and monitor the prescribing pattern of antimicrobials for suitable modifications in prescribing patterns to increase the therapeutic benefits as well as cost effective health care services. $^{4,6}$

The Anatomical Therapeutic Chemical (ATC) classification / defined daily dose (DDD) system is a tool for presenting drug utilization research in order to improve quality of drug use and is recommended by the World Health Organization (WHO) as the international standard for drug utilization studies. ${ }^{7}$

So, keeping these in view, present study was done with primary objectives:

- To assess the prescription patterns of AMAs in the form of frequency of class and agents of AMAs according to WHO-ATC classification in ICU of a tertiary care teaching Hospital.

- To find out the utilization of AMAs in ICU as measured by DDD/ 100 bed-days (WHO / DDD).

- $\quad$ To measure the incidence and types of ADRs in ICU and with secondary objective to assess the rationality of use of AMAs in the medical ICU of a tertiary care hospital.

\section{METHODS}

Study Design: After Institutional ethical committee approval this prospective observational study was carried out in the Medical ICU to assess the prescription patterns of AMAs and occurrence of ADR if any during the admitted period of patients in ICUs for a period of two months in the Medical ICU of a Tertiary Care teaching Hospital in North Eastern Part of India.

\section{Inclusion and exclusion criteria}

All the patients who were admitted during the study period in the ICU and given written informed consent to participate in the study were included in this study. The patients who were transferred to other wards from ICU / were discharged or died within 24 hours of admission to ICU were also excluded from the study. ${ }^{2,4,6,8}$

Outcome variables: $:^{2,7}$

- Type of AMA class and agents used.

- Number of AMAs prescribed

- Percentage of oral and parenteral route of administration.

- $\quad$ Prescription frequency of individual AMAs.

- Prescription frequency of class of AMAs.

- $\quad$ Length of hospital stay.

- Classification of AMAs used as per ATC code.

- Utilization of AMAs in ICUs by calculation of DDD/ 100 bed - days. (WHO-DDD).

- Incidence of ADR reactions during study period and causality assessment of ADRs were done according to WHO-UMC criteria.

- Rationality of use of AMAs in ICU.

Data Source and Sampling Methods: The case record sheets of all the patients admitted in ICU were utilized for study of utilization pattern of AMAs and any occurrence of ADRs during the stay of the patient in the Medical ICU. All the patients were also interviewed (if medically permitted) daily during their hospital stay and followed up till he / she is discharged from ICU.

Study tool, data measurement and format of analysis:2,6-10

All the patients admitted in ICU during the study period were explained clearly about the purpose and nature of the study and written informed consent was taken before including them in the study. All the patients were interviewed daily. Every patient was followed up till discharged from ICU and their case record sheets were reviewed for recording necessary information's as per predesigned case record form. The following parameters were recorded.

- $\quad$ Patient's demographic profile.

- Short history, clinical presentation and diagnosis with associated co morbidities.

- Date of admission and date of discharge in ICUs.

- Drugs, especially antimicrobial class and agents used with dose, dosages form, route of drug administration, frequency, start and stop dates of antimicrobial and duration of administration. 
- Any ADR observed by the investigator or treating physician were recorded in ADR reporting form adopted by Central Drug Standard Control Organization (CDSCO) and copy of the same were reported in ADR monitoring center of the institution.

- Causality assessment of ADRs were done according to WHO-UMC criteria.

- Rationality of use of AMAs was assessed as follows: ${ }^{6}$

- The therapy was considered rational if the antimicrobial use and its route of administration, dose, frequency and duration of use are considered appropriate for infection.

- Therapy was considered irrational if the antimicrobial is used without indication, prophylaxis under circumstances of unproven efficacy or by clearly inappropriate route, dose or preparation for that indication.

- Therapy was considered questionable when insufficient clinical or laboratory data is present to enable the therapy to be classified as clearly rational or irrational e.g. patients of congestive heart failure having cough but do not know that cough is due to CHF or infection then treatment with antimicrobial agent considered questionable.

The DDD per 100 bed - days (WHO-DDD) was calculated by the formula: ${ }^{11-14}$

DDD $/ 100$ bed-days $=$ Total No. of units administered in a given period $(\mathrm{mg}) \times 100$

DDD of Drug $(\mathrm{mg}) \times$ number of days in the study period $\times$ number of beds $\times$ occupancy index

Occupancy index $=\underline{\text { Total number of inpatient service days for a given }}$ period

Total inpatient bed count $\times$ number of days in the period

\section{Sample size}

All the patients who were admitted during the study period of two months were included in the study considering the inclusion and exclusion criteria.

\section{Statistical analysis}

The data was subjected to statistical analysis using Microsoft excel spread sheet.

Data have been expressed as absolute numbers with or without percentages, as means with standard deviation. Descriptive statistical calculations done in Microsoft 2007 excel.

\section{Confidentiality}

All collected information about the patients kept confidential and is accessible only to the investigator and the guide.

\section{RESULTS}

During the study period, a total 127 subjects who were admitted in Medical ICU and also met inclusion criteria were recruited in this study. Of the 127 recruited patients, $80(62.99 \%)$ were male and $47(37.01 \%)$ were female in ratio of 1.7:1. The age of the patients ranged from 13 to 93 years old with average of $51.3 \pm 18.3$ years. The Mean \pm SD age of male and female patients were found to be $54 \pm 17.81$ years and $46.8 \pm 18.26$ years respectively. Age and sex wise distribution of the patients shown in Table 1.

Table 1: Distribution of patients admitted in medical ICU according to age and sex.

\begin{tabular}{|lllll|}
\hline $\begin{array}{l}\text { Age } \\
\text { group }\end{array}$ & Patients & $\begin{array}{l}\text { Percentage } \\
\text { among } \\
\text { total } \\
\text { subjects }\end{array}$ & $\begin{array}{l}\text { Male } \\
(\% \\
\text { among } \\
\text { age } \\
\text { group) }\end{array}$ & $\begin{array}{l}\text { Female } \\
\text { (\% among } \\
\text { age group) }\end{array}$ \\
\hline $\begin{array}{l}\leq 35 \\
\text { years }\end{array}$ & $\begin{array}{l}27 \\
(21.26 \%\end{array}$ & 21.26 & $\begin{array}{l}13 \\
(48.15)\end{array}$ & $14(51.85)$ \\
\hline $\begin{array}{l}36-65 \\
\text { years }\end{array}$ & $\begin{array}{l}80 \\
(62.99 \%)\end{array}$ & 62.99 & $52(65)$ & $28(35)$ \\
\hline $\begin{array}{l}>65 \\
\text { years }\end{array}$ & $\begin{array}{l}20 \\
(15.75 \%)\end{array}$ & 15.75 & $15(75)$ & $5(25)$ \\
\hline Total & $\begin{array}{l}127 \\
(100 \%)\end{array}$ & $100 \%$ & $\begin{array}{l}80 \\
(62.99 \%)\end{array}$ & $47(37.01 \%)$ \\
\hline & $\begin{array}{l}\text { Mean } \pm \text { SD } \\
\text { of Age }\end{array}$ & $54 \pm 17.81$ & $46.8 \pm 18.26 *$ \\
\hline
\end{tabular}

$* \mathrm{P}=0.140338$ when compared with age of female

Out of the 127 patients, $21(16.54 \%)$ patients died, 73 $(57.48 \%)$ patients were transferred to ward after improvement, 4 patients either referred or left against medical advice and $29(22.83 \%)$ patients were discharged from ICU. There were total 201 morbidities at a Mean \pm SD of $1.58 \pm 0.82$ per patients. Morbidity Pattern of the patients admitted in ICU has been shown in Table 2.

During study period in 883 occasions drugs were prescribed at an average of $6.95 \pm 3.14$ per patient. There were 174 prescriptions of AMAs at an average of $1.37 \pm 1.12$. Out of these total 127 admitted patients, 102 $(80.31 \%)$ patients received AMAs and 25 (19.69\%) didn't. There were total 174 prescriptions of AMAs for 102 patients who received AMAs, at average of $1.71 \pm 0.99$ AMAs per prescription containing AMAs. From this study it was found that Betalactam antibiotics were the most frequently (72.99\%) prescribed class of AMAs. 127 prescriptions out of 174 antimicrobial prescriptions were of this group. Among the Betalactam, Cephalosporin were prescribed in $62(35.63 \%)$ occasions and other Betalactams were prescribed in $65(37.36 \%)$ occasions. Meropenem was prescribed in $41(23.56 \%)$ occasions which was the most commonly prescribed individual AMA followed by Ceftriaxone which was prescribed 37 $(21.26 \%)$ occasions. Out of the total 174 AMAs prescriptions, in 164 (94.25\%) occasions, AMAs were prescribed parentally and oral prescriptions were only in $10(5.75 \%)$ occasions to administer AMAs like 
Ciprofloxacin, Azithromycin, Rifaximin, Doxycycline and Acyclovir.

Table 2: Morbidity pattern of the patients $(\mathrm{N}=127)$ admitted in the medical ICU for two months study period.

\begin{tabular}{|ll|}
\hline Morbidity & Frequency \\
\hline Diabetes mellitus & 25 \\
\hline Myocardial infarction & 20 \\
\hline Hypertension & 20 \\
\hline Septicemia & 18 \\
\hline CVA & 15 \\
\hline Ischemic heart disease & 12 \\
\hline Diabetic ketoacidosis & 8 \\
\hline LRTI & 8 \\
\hline Chronic kidney disease & 6 \\
\hline COPD & 5 \\
\hline Upper GI bleeding & 5 \\
\hline Sepsis & 4 \\
\hline Congestive heart failure & 4 \\
\hline Encephalopathy & 4 \\
\hline Poisoning & 4 \\
\hline Pancreatitis & 4 \\
\hline UTI & 3 \\
\hline Meningitis & 3 \\
\hline Hanging & 3 \\
\hline Cardiomyopathy & 2 \\
\hline Corpulmonale & 2 \\
\hline Eclampsia & 1 \\
\hline Acute kidney injury & 1 \\
\hline Snake bite & 1 \\
\hline Bulbar palsy & 1 \\
\hline Severe malaria & 1 \\
\hline
\end{tabular}

Table 3: Number of antimicrobial agents prescribed in medical ICU during two months of study period.

\begin{tabular}{|lll|}
\hline $\begin{array}{l}\text { Number of antibiotics } \\
\text { prescribed }\end{array}$ & $\begin{array}{l}\text { Number of } \\
\text { patients }\end{array}$ & Percentage \\
\hline 0 & 25 & $18.90 \%$ \\
\hline 1 & 57 & $44.88 \%$ \\
\hline 2 & 27 & $20.47 \%$ \\
\hline 3 & 11 & $9.45 \%$ \\
\hline 4 and above & 7 & $6.30 \%$ \\
\hline $\begin{array}{l}\text { Total antibiotics } \\
\text { prescription }=180\end{array}$ & 127 & $100 \%$ \\
\hline $\begin{array}{l}\text { Number of Patients } \\
\text { received AMAs }=103\end{array}$ & \\
\hline $\begin{array}{l}\text { Average number of } \\
\text { antibiotics per patients } \\
\text { who received AMA }\end{array}$ & $1.71 \pm 0.99$ & \\
\hline $\begin{array}{l}\text { Average number of } \\
\text { antibiotics per patients } \\
\text { Among total patients } \\
\text { admitted in ICU }\end{array}$ & $1.37 \pm 1.12$ & \\
\hline
\end{tabular}

Out of 127 patients $74(58.27 \%)$ patients were suffering from single morbidity rest of the 53 patients were suffering from two or more morbidities. Number of Antimicrobial agents prescribed per patient has been shown in Table 3 and frequency pattern of prescription of different AMA have been shown in and also in Figure 1.

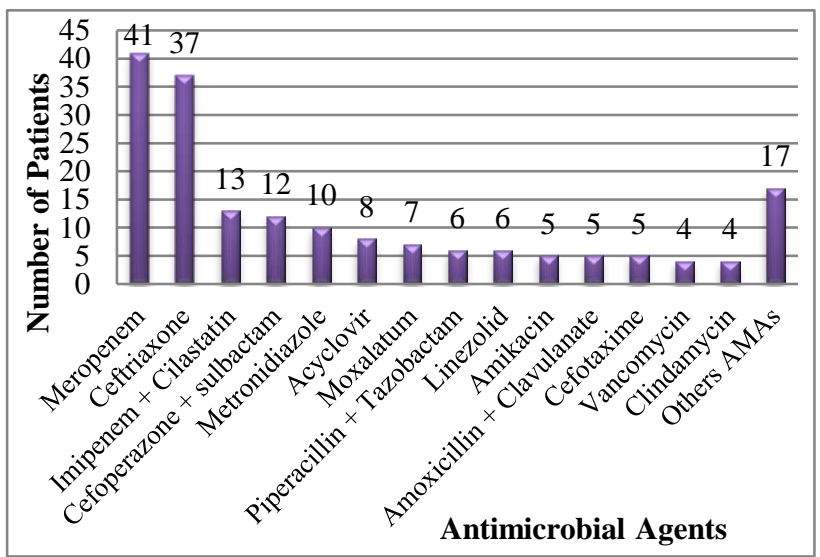

Figure 1: Number of patients received different Antimicrobial Agents (AMAs).

No AMAs were prescribed in generic name. Out of 102 patients who received AMAs, in $28(27.45 \%)$ patients the AMAs prescribing was leveled as irrational and in 8 $(7.84 \%)$ it was leveled as questionable because of one or more of the following reasons like prescribing two AMAs at a time from same group without definite indication, changing the AMAs without definite indication or support of antibiogram or proper explanation or standard treatment guideline, prescribing AMAs or changing the AMA which is not comparable with the results of culture and sensitivity report, using prophylactic AMAs without justification. Pattern of rationality against the number of AMAs prescribed has been shown in Figure 2. In Figure 3 the indications of use of AMAs have been depicted.

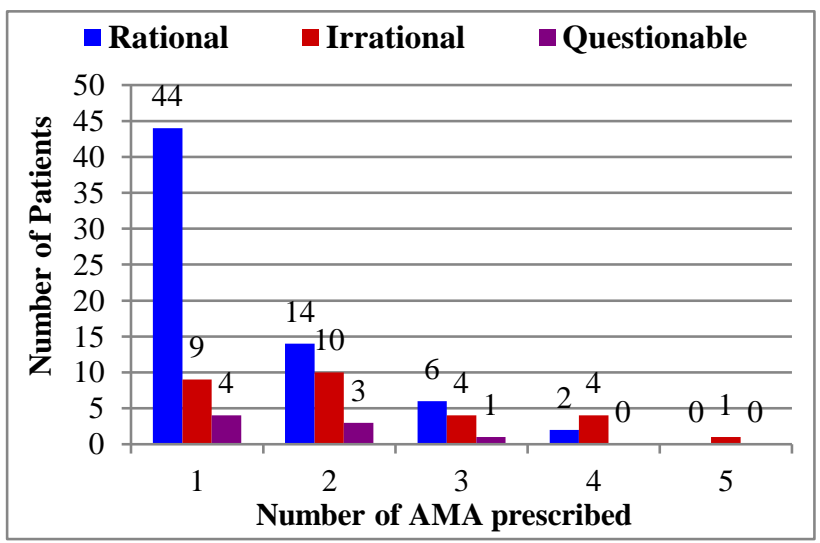

Figure 2: Pattern of rationality against the number of AMAs prescribed.

The Length of stay (LOS) of patients in ICU was ranging from 1 to 26 days with an average of $4.42 \pm 3.49$ days. Out of total 127 subjects 84 subjects received either one or two 
AMAs and 18 subjects received 3 or more AMAs and 25 patients received no AMAs during their stay in ICU and their average days of ICU stay was $4.19 \pm 3.17,6.2 \pm 5.8$ days and $3.88 \pm 1.48$ respectively. During the 60 days study period total patient days in 10 bedded Medical ICU was 561 days with occupancy Index of 0.935 .

From 127 study subjects 54 blood samples, 45 urine samples, 12 sputum samples and 4 CSF samples were tested for culture and sensitivity test. Out of these samples only in 11 samples different organisms namely of Enterococci, E coli, Pseudomonas and Staphylococcus were isolated. Isolated organisms were sensitive to any one or more AMAs like Linezolids, Meropenems, vancomycin, Doxycycline, Ofloxacin, Ciprofloxacin, Nitrofurantoin, Levofloxacin, Ceftriaxone, Pipercillin, Amikacin, Tetracycline.

Table 4 enlists AMAs prescribed during the study period in Medical ICU along with their classification of AMAs used as per ATC code. Utilization pattern of AMAs in ICUs by calculation of DDD/ 100 bed-days. (WHO-DDD) also has been depicted in Table 4 .

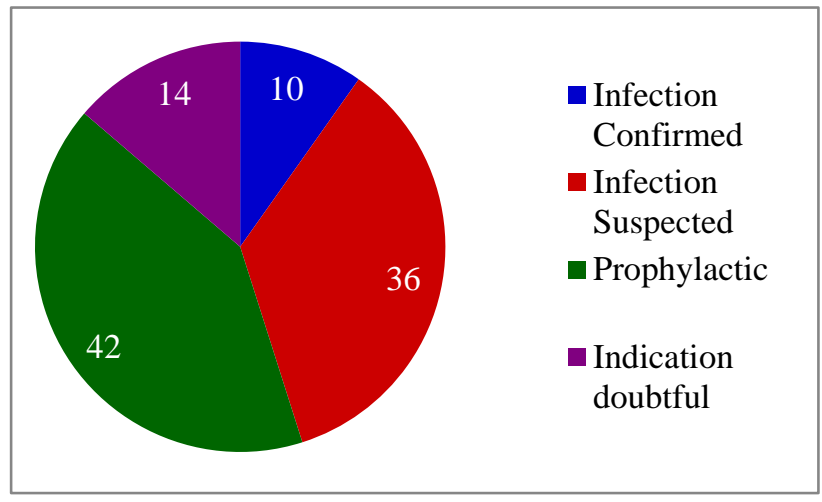

Figure 3: Indication of use of AMAs has been depicted.

Table 4: WHO DDD per 100 bed days of Antimicrobial agents used in patients admitted in the Medical ICU for two months study period.

\begin{tabular}{|c|c|c|c|c|c|c|}
\hline Class & AMA & ATC Code & $\begin{array}{l}\text { No of patient } \\
\text { received }\end{array}$ & $\begin{array}{l}\text { Total } \\
(\mathrm{mg})\end{array}$ & DDD mg & $\begin{array}{l}\text { DDD/100 } \\
\text { bed days }\end{array}$ \\
\hline Carbapenems & Meropenem & J01DH02 & 41 & 689000 & 2000 & 61.41 \\
\hline Cephalosporin & Ceftriaxone & J01DD04 & 37 & 272000 & 2000 & 24.24 \\
\hline Carbapenems & Imipenem Cilastatin & J01DH51 & 13 & 69500 & 2000 & 6.19 \\
\hline Cephalosporin & Cefoperazone + sulbactam & J01DD62 & 12 & 150000 & 4000 & 6.68 \\
\hline Imidazole & Metronidazole & J01XD01 & 10 & 51000 & 1500 & 6.06 \\
\hline Anti viral & Aciclovir & D06BB03 & 8 & 70300 & 4000 & 3.13 \\
\hline Cephalosporin & Moxalactam & J01DD06 & 7 & 102000 & 4000 & 4.55 \\
\hline Penicillins & Piperacillin + Tazobactam & J01CR05 & 6 & 238500 & 14000 & 3.04 \\
\hline Oxazolidinone & Linozolid & J01XX08 & 6 & 25200 & 1200 & 3.74 \\
\hline Aminoglycoside & Amikacin & J01GB06 & 5 & 22000 & 1000 & 3.92 \\
\hline Penicillins & Amoxicillin Clavulanate & J01CR02 & 5 & 61200 & 1000 & 10.91 \\
\hline Cephalosporin & Cefotaxime & J01DD01 & 5 & 61600 & 4000 & 2.75 \\
\hline Glycopeptide & Vancomycin & J01XA01 & 4 & 18000 & 2000 & 1.60 \\
\hline Lincosamide & Clindamycin & J01FF01 & 4 & 21600 & 1200 & 3.21 \\
\hline Fluroquinolone & Moxifloxacin & J01MA14 & 2 & 4000 & 400 & 1.78 \\
\hline Macrolides & Azithromycin & J01FA10 & 2 & 5500 & 500 & 1.96 \\
\hline $\begin{array}{l}\text { Intestinal } \\
\text { antiinfective }\end{array}$ & Rifaximin & A07AA11 & 2 & 11000 & 600 & 3.27 \\
\hline Aminoglycoside & Netilmycin & S01AA23 & 1 & 500 & 350 & 0.25 \\
\hline Aminoglycoside & Streptomycin & A07AA04 & 1 & 14250 & 1000 & 2.54 \\
\hline Antimalarial & Artesunate & P01BE03 & 1 & 360 & 280 & 0.23 \\
\hline Broad spectrum & Chloramphenicol & J01DA01 & 1 & 10000 & 3000 & 0.59 \\
\hline Cephalosporin & Ceftazidime & J01DD02 & 1 & 14000 & 4000 & 0.62 \\
\hline Fluroquinolone & Ciprofloxacin & J01MA02 & 1 & 2000 & 1000 & 0.36 \\
\hline Fluroquinolone & Levofloxacin & J01MA12 & 1 & 2000 & 500 & 0.71 \\
\hline Tetracycline & Tigecycline & J01AA12 & 1 & 200 & 100 & 0.36 \\
\hline Macrolides & Clarithromycin & J01FA09 & 1 & 900 & 500 & 0.32 \\
\hline Tetracycline & Doxycycline & J01AA02 & 1 & 800 & 100 & 1.43 \\
\hline Antifungal & Voriconazole & $\mathrm{J} 02 \mathrm{AC} 03$ & 1 & 1600 & 200 & 1.43 \\
\hline & & \multicolumn{4}{|l|}{ Total } & 157.29 \\
\hline
\end{tabular}


Out of the all study subjects only one male patient, 52 years old who was admitted in ICU with diagnosis of septicemia and received Meropenem, Vancomycin, Levofloxacin and Acyclovir developed ADR in the form of hyponatremia. This ADR was reported to ADR monitoring center of institution running under Pharmacovigilance program of India.

\section{DISCUSSION}

Antibiotic resistance is increasing day by day and for management of infectious diseases antibiotic resistance has poised a significant threat. ${ }^{1}$ Moreover AMAs are most frequently prescribed drugs in ICU. ${ }^{2,11}$ Increasing multidrug resistance with limited availability of newer agents there is urgent need for vigilant surveillance, stringent infection control as well as rational antibiotic prescription $1 .^{1,15}$ The clinical setting in the medical ICU warrants the use of drugs from various drug classes. Rational prescription of drugs is essential for better patient care. The first step in any intervention programme to improve drug utilization is to assess the extent of existing problem in prescribing. ${ }^{16}$ Antibiotics utilization study can help to have bird's eye view regarding the present practice of prescribing antibiotics and timely intervention can help in promoting the habits of rational use of antibiotics. So, the antibiotic utilization study is still relevant even today.

The demographic parameters of the patients revealed that the number of male patients $(62.99 \%)$ admitted in ICU was almost double to that of female $(37.01 \%)$. The mean age was of patients was $51.3 \%$ and this observation of the present study is in conformity with the study of Anand $\mathrm{N}$ et al, Pandiamunian J, Alamchandani RR and Patanaik SK et al, done at Mangalore, Karnataka, Puducherry, Vadodara, Gujarat and Bhubaneswar respectively. 2,4,17,18 This finding suggest that more male patients are admitted in ICU and likely reason for this finding could be that male population has more access to medical facility compared to female who even in critical illness are reluctant to utilize health care facilities. This study also revealed that the maximum number of the patients belongs to the age group of 35 to 65 years $(62.99 \%)$ of age and this finding is similar to the studies done in different parts of India. ${ }^{2,4,11,18}$

In the present study the average length of stay (LOS) in ICU per patient was $4.42 \pm 3.49$ days which is in accordance with the finding of Anand $\mathrm{N}$ et al, and other studies done in different parts of India. . $10,13,14,19-21$ In this study it was revealed that out of 127 patients, $102(80.31 \%)$ patients received at least one AMA and this result is in conformity with the finding of similar studies. ${ }^{2,5,10}$ Total 883 occasions drugs were prescribed at an average of $6.95 \pm 3.14$ per patient for 127 patients and this result is comparable with the study done by Patel SR (6.87), Shobha P (6.9), Williams A (6.23). ${ }^{7,13,22}$ In accordance with the finding of Pandiamunian J, and Kaur S et al, and of other researcher, present study also revealed that PPI $(81.1 \%)$ was one of the most common non- AMA drug prescribed in ICU setup. . $^{46,21-23}$
Patients with wide variety of clinical conditions were admitted in ICU. Myocardial Infarction, Septicaemia, Cerebrovascular accidents (CVA), Respiratory infections, Acute and Chronic Kidney injury were the common diagnosis which warned admissions in ICU and this observation is in conformity with the findings of Anand $\mathrm{N}$ et al, Pandiamunian J, Badar VA and Patanaik SK et al. ${ }^{2,4,5,18}$ Diabetes and hypertension were two common co morbid conditions among the patients who got admitted in medical ICU and this finding is comparable with the finding of Kaur S et al. ${ }^{23} 58.27 \%$ of the admitted patients had only one morbid condition, whereas rest $41.73 \%$ of the patients had two or more morbid conditions and this result is similar to the finding of Anand $\mathrm{N}$ et al, and Bansal D et al. ${ }^{2,15}$

Overall mortality rate was found to be $16.54 \%$ in this study and this is in conformity with the finding of similar study done by Anand N et al. 2016' and Shankar PR. ${ }^{2,20}$ However many studies reported that ICU mortality is more than $30 \%$. $^{13,17,19}$

Out of the total 883 prescriptions of drug, 174 (19.71\%) prescriptions were of AMA, and this finding is inconformity with the finding of other study done at Gandhinagar, Gujarat. ${ }^{719}$ Out of 127 admitted patients, 102 patients received AMA at an average of $1.71 \pm 0.99$ per patient and this is in conformity with the finding of Anand $\mathrm{N}$ et al, and Amit GS et al, who reported the average prescription of AMAs as 1.73 and 1.74 respectively per patient. $^{2,19}$ Out of the 102 patients who received AMA, 57 $(55.88 \%)$ patients received only one AMA and rest 45 (44.12\%) patients received more than one AMA and this finding is in conformity with the finding of other researchers. $^{2}$

In the present study the most commonly prescribed class of AMA was Betalactam group which is in accordance with the finding of studies done by Anand $\mathrm{N}$ et al, Drupad HS et al, Patel SR et al, however most commonly prescribed AMA was Meropenem (23.56\%) followed by Ceftriaxone and this is in contrary to the finding of the other studies where ceftriaxone was the most commonly prescribed AMA. ${ }^{2,4-7}$ In this study $21.26 \%$ of the patients received ceftriaxone among the 102 patients who received one or more AMAs and this frequency of use of ceftriaxone was comparable with the finding of other studies. . $^{2,16}$ The present study revealed that Meropenem, Ceftriaxone, Imipenem + Cilastatin, Cefoperazone + sulbactam and metronidazole are the five most commonly prescribed AMAs in ICU and this is in contrary to the studies done in different parts of the country. ${ }^{4-7,10,13,19,21}$ This may be due to the prevalence different pattern of infecting organisms. In this study the choice of Meropenem was empirical without following any standard treatment guideline (STG) and it may be due to its broadest spectrum activity.

The DDD system is most frequently used in academic articles and reports and a tool for national and international 
comparison of drug consumption. The number of DDDs for prescribed antimicrobials in this study was calculated, which serve as a baseline data for comparison in future studies that can be done in similar setup to identify the trends in drug consumption over years. These data can also be used for comparison of drug consumption in different parts of this country and international comparisons. In the present study the pattern of AMA use in DDD / 100 bed days was analyzed. The utilization of AMAs in total was 157.29 DDD / 100 Bed days and this consumption is in conformity with the study of Anand $\mathrm{N}$ et al (148.97). ${ }^{2}$ In the present study the consumption in DDD / 100 Bed days of Meropenem, Ceftriaxone and Amoxicillin Clavulanate was $61.41,24.24$ and 10.91 respectively and this consumption pattern is much higher than that of other parts of the country. ${ }^{7,11,13}$ On reviewing similar studies done by Williams A et al, Arathy R et al, authors found that the consumption of restricted AMA, Meropenem in DDD / 100 bed days was 16.47 and 2.26 respectively and this is in contrary to the finding of present study. ${ }^{13,21}$

In this study, $94.25 \%$ of prescribed AMAs were given parenterally and $5.75 \%$ by orally. This finding is comparable with the finding of Alamchandani RR et al, and Patanaik SK et al. ${ }^{17,18}$

On analyzing the indications of AMAs use present study revealed that in $9.8 \%$ cases showed confirmed diagnosis of infections and in rest of the patient AMAs were used either prophylactically or empirically. This finding is in conformity with the finding of Patel SR et al, Williams A et al. ${ }^{7,13}$ In the present study in considerable occasions the use of AMAs was either irrational or questionable which needs to be addressed urgently.

The important limitations this study includes its short observation period. Since residents doctors rotate through the wards on a monthly basis, the study reflects the prescribing patterns of a specific group only. Thus, it might difficult to generalize the results.

\section{CONCLUSION}

This study revealed that patients got admitted with wide spectrum of diagnosis and received variety of costly AMAs empirically. The proportion of AMA use for proven infection was low and efforts to prescribe AMAs on sound bacteriological basis should be encouraged. Empirical therapy should be used only in an emergency and should be guided by the antimicrobial policy of the hospital, common causative organisms of nosocomial infection and local resistance pattern. These steps will ensure rational prescribing of antimicrobial agents and also decrease the risk of development of resistance to antimicrobial agents. The hospital staff should regularly be made aware of recent updates, changing patterns of resistance, and availability of new antimicrobials. The presence of clinical pharmacologist in every ICU setup will ensure rational use of antimicrobials in a cost effective manner. The antimicrobial stewardship program is a must for every hospital. A committee should be involved to prepare and ensure the availability of standard treatment protocol and to monitor the prescription pattern of AMAs regularly for strict implementation of institutional antimicrobial policy. This study also highlights the need for rationalizing drug therapy in the ICU.

This study will serve to provide a data regarding the current prescribing pattern of AMAs and initiate suitable interventions towards the rational use of antibiotics.

\section{ACKNOWLEDGEMENTS}

This study was done under STS programme by ICMR. The authors are grateful to the ICMR, Principal Agartala Govt. Medical Collage and GBP Hospital Agartala, Tripura for providing the necessary facilities to carry out this study.

Funding: No funding sources

Conflict of interest: None declared

Ethical approval: The study was approved by the Institutional Ethics Committee

\section{REFERENCES}

1. Meher BR, Mukharjee D, Udaishankar. J Chem Pharm. Res. 2014;6(7):1847-9.

2. Anand N, Nayak IMN, Advaitha MV, Thaikattil NJ, Kantanavar KA, Anand S. Ind J Criti Care Medici. 2016;20(5):22-7.

3. Sachidananda Adiga MN, Alwar MC, Mirabel Pai RSM, Usha S Adiga. Onli J Healt and Alli Scienc. 2009;8(4):1-4.

4. Pandiamunian J, Somasundaram G. A study on Prescribing Pattern of Anti Microbial Agents in the Medical Intensive care unit of a tertiary care teaching hospital in Puducherry Union Territory, South India. Int J Pharm Pharm Sci. 2014;6(3):235-8.

5. Badar VA, Navale SB. Study of prescribing pattern of antimicrobial agents in medicine intensive care unit of a teaching hospital in central India. JAPI. 2012;60.

6. Drupad HS, Nagabushan H, Prakash GM. Prospective and Observational Study of Antimicrobial Drug Utilization in Medical Intensive Care Unit in a Tertiary care Teaching Hospital. Int J Pharm Resear. 2016;6(1):13-7.

7. Patel SR, Shah AM, Shah RB, Buch JG. Evaluation of drug utilization pattern of antimicrobials using ATC / DDD system in intensive care unit of a tertiary- care teaching hospital. Inte $\mathbf{J}$ Med Scien and Publi Healt. 2016;5(1):80-4.

8. Kathiria JM, Sattigeri BM, Desai PM and Patel SP. A study of adverse drug reactions in patients admitted to intensive care unit of a tertiary care teaching rural hospital. Int J Pharm Pharm Sci. 2013;5(1):160-3.

9. Saravanan SS, Kavitha P, Ponnuswamy TK. Patterns of Adverse Drug Reactions in the Medical Intensive Care Unit of an Indian Tertiary Care Hospital. Int $\mathbf{J}$ Pharmaceu Bio Archiv. 2014;5(3):64-8. 
10. Bansal D, Mangala S, Undela K, Gudula K, D'cruse S, Sachdev A, et al. Measurement of Adult Antimicrobial Drug Use in Tertiary Care Hospital Using Defined Daily Dose and Days of Therapy. Indian J Pharmaceu Scien. 2014;76(3):211-7.

11. Shelat PR, Gandhi AM, Patel PP. A Study of ine Dose in Drug Utilization Pattern According to Daily Define Dose in Intensive Care Unit (ICU) at Tertiary Care Teaching Hospital, India. J You Pharmacis. 2015;7(4):349-58.

12. Choudhury DK, Bezbaruah BK. Prescribing Pattern of Analgesic in Orthopedic In-patient Department at Tertiary Care Hospital in Guwahati, Assam, Northeast India. Ind J Pharmacol. 2016;48(4):377-81.

13. Williams A, Mathai AS, Phillips AS. Antibiotic prescription patterns at admission into a tertiary level intensive care unit in Northern India. J Pharm Bioallied Sci. 2011;3:531-6.

14. Patel MK, Barvaliya MJ, Patel TK, Tripathi CB. Drug Utilization Pattern in Critical Care Unit in a Tertiary Care Teaching Hospital in India. Int J Crit Illn Inj Sci. 2013;3(4):250-5.

15. Mahajan B, Kaushal S, Chopra SC. A drug Utilization study of Antimicrobial agents (AMAs) in the intensive Care Units (ICUs) at Medical College Hospital of North India. J K Science. 2013:15(3):129-32.

16. John LJ, Devi P, John J, Guido S. Drug utilization study of antimicrobial agents in medical intensive care unit of a tertiary care hospital. Asian J Pharm Clin Res. 2011;4:81-4.

17. Alamchandani RR, Khubchandani PR. A Study Evaluating Appropriateness of Utilization Pattern of Antimicrobials in Patients Admitted in Medical Intensive care unit of Tertiary Care Teaching Rural Hospital. Int J Pharm Pharm Sci. 2015;7(5):101-4.
18. Patanaik SK, Pattanayak C, Prasad A, Chauhan AS. Drug Utilization Pattern in an Intensive Care Unit Setting in Eastern India. Int $\mathbf{J}$ Basic Clin Pharmacol. 2015;4(6):1136-41.

19. Amit GS. Drug use evaluation study in a tertiary care corporate hospital with special reference to use of antibiotics in ICU department. Int J Adv Pharm Biol Chem. 2013;2:179-89.

20. Shankar PR, Partha P, Dubey AK, Mishra P, Deshpande VY. Intensive care unit drug utilization in a teaching Hospital in Nepal. Kathmandu Univ Med J. KUMJ. 2005;3:130-7.

21. Arathy R, Chacko J, Pillai S, Bhanu A, Raphael R, Jalajakumari M. Drug Utilization in Medical Intensive Care Unit: A Retrospective Analysis from a Tertiary Care Teaching Hospital. Int J Basic Clin Pharmacol. 2016;5(4):1201-4.

22. Shobha P, Sunitha M. Evaluation of Rational Drug Use Pattern Using WHO Prescribing Indicators in a Medical Intensive Care Unit of a Tertiary Teaching Hospital in Kerala, India. Int J Basic Clin Pharmacol. 2017;6(6):1328-32.

23. Kaur S, Rajagopalan S, Kaur N, Shafiq N, Bhalla A, Pandhi P, et al. Drug utilization study in medical emergency unit of a tertiary care hospital in North India. Emerg Med Int. 2014;5. Article ID 973578.

Cite this article as: Ray D, Datta S. A study on antimicrobial agents utilization pattern using anatomical therapeutic chemical / daily defined dose system and adverse drug reaction pattern in the intensive care unit of a tertiary care teaching hospital in North Eastern state of India. Int J Basic Clin Pharmacol 2018;7:1612-9. 